\title{
Rangelands In Jordan And Tunisia
}

\author{
Challenges of the past and suggested solutions for \\ future sustainable management.
}

\author{
By Taoufik Ksiksi', Mohamed K. J. El-Shatnawi ${ }^{2}$ and Salah Chouki ${ }^{3}$
}

$\mathrm{R}$ angelands in Jordan and Tunisia play an important role in the economy of both countries. However, historical overuse of these systems has made it difficult and sometimes impossible to bring about remedial solutions. Following is an overview of the historical development of rangelands in Jordan and Tunisia and suggested ways to prevent further declines and develop sound management options for the benefit of the users, managers and the respective societies in general.

\section{Jordanian Rangelands}

In the Middle East, grazing of native rangelands began 11,000 years ago. Jordanian rangelands are mostly arid or semiarid, rainfall varies from less than 100 to $400 \mathrm{~mm}$. The climate in Jordan, being typical of the Mediterranean environment, is characterised by mild-humid winters and long hot, dry summers, and very short growing season with high variability in rainfall amount and distribution. Jordan is small $\left(90,000 \mathrm{~km}^{2}\right)$ but has five different rainfall zones: Jordan valley, arid lands, marginal lands, semiarid lands and semi-humid mountains.

Aridlands occupy more than $90 \%$ ( 8.5 million hectare) of the country's area and are distributed over seven ecological regions. Therefore most of the Jordanian rangeland may be considered as an ecosystem under non-equilibrium. In the Mediterranean Basin, rangeland production is closely relat-

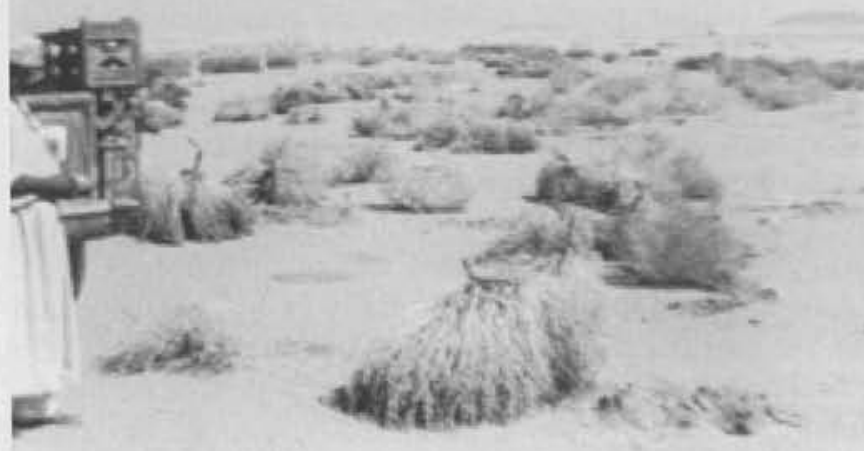

Jordan cutting shrub. ed to rainfall variability. The annual total evapotranspiration is about $1300 \mathrm{~mm}$.

Rangelands and forests have deteriorated due to long term abuses such as overgrazing, cultivation, and deforestation. Jordan asked for assistance in range improvement programs from the Food and Agriculture Organisation (FAO) of the United Nations. There is a need to start a program of improvement to repair the damage done through 100 centuries of overuse. Overuse caused advanced vegetation and soil deterioration. There is an increasing awareness by stakeholders of the urgent need for strategies and programs that aim at improving and managing rangelands.

Jordan has over 2.6 million sheep and one million goats, and the amount of supplemented feedstuff is estimated around 444 thousand metric tons. Systems of livestock production in Jordan are nomadic, semi-sedentary, mixed farming, intensive production and small family holdings. However, pastoral systems in the Middle East rely primarily on nomadism, transhumance and integrated cereal-livestock farming. Nomadism and transhumance dominate in arid areas. Integrated cereal-livestock farming system is used around villages and cities in the semiarid areas, which receive more than $250 \mathrm{~mm}$ average annual rainfall.

Nomadic herders have no permanent base. They take all their provisions with them as they move with their livestock. A 1994 report noted that the general nomadism features were (1) nomadism socio-political framework is tribalism; it is the loyalty of an individual to the tribe; (2) the presence of a hierarchical social structure in the tribe; (3) the decision which affects the individual family is taken by the head of the family. However, at times, some major decisions are taken by the family council of elders; (4) Illiteracy percentage among pastoralist is high; and (5) drought and high variability in rangelands productivity causes high economic losses and instability.

During the last two decades the characteristics of pastoralism have changed due to:

a. legal changes in the pasture areas from tribes and subtribes ownership to open free grazing or nationalised ranges and neglecting the old Hema (the old range reserve system developed in the Middle East to control common grazing)

b. the cultivation of marginal areas of grassland that receive good annual rainfall $(200-300 \mathrm{~mm})$, 
c. the overstocking around settlements and wells caused rapid, huge and sometime irreversible damages to vegetation and soil of the arid fragile rangelands,

d. the rhythmic movement from one area to another according to the availability of forages was reduced due to spread of livestock moving vehicles, limiting progressive grazing.

e. government feed subsides

f. restriction of movements through borders of neighbour countries

g. other various sociological, economical, political and legal problems.

The present seasonal livestock feed source in Jordan is to graze on marginal lands for 3 months, to graze on cereal stubble in rain-fed areas for 4 months, to graze on natural pasture in rain-fed areas for 1.5 months and to feed supplements for 3.5 months. The big challenge facing the country is how to raise productivity of the arid rangelands.

A well-organised program for the development of rangelands would have considerable economic and social benefits. Further delay in providing support to restoring these areas poses serious hazards, such as progressive erosion, threat of desertification and lowering income, which leads to migration to urban centres.

Research projects have been started to find adapted and productive species for reseeding, and to increase water harvesting in these arid rangelands. Lack of progress in range improvement appears to be a result of poor long-term integrated planning, failure to recognise the seriousness of rangeland problems and lack of innovation to address them. Planners recognise the urgent need to gain self sufficiency in agricultural products using the potential of natural wildlands. For full recovery of these severely depleted lands, a range development and improvement program must be implemented to establish and maintain valuable forage resources.

\section{Tunisian Rangelands}

Like in Jordan, population growth in Tunisia during the past forty years has triggered a dramatic increase of livestock numbers in the country. Sheep and goat population has increased by more than two-fold between 1964 and 2000. Simultaneously, the large nomadic herds that grazed the area in the past have been replaced by small poorly managed flocks, as the livestock systems changed from nomadic to sedentary farming. This new lifestyle has been accompanied by converting the most fertile grazing lands to cereal, olive, or almond production and establishing yearlong grazing of the remaining rangelands.

Little attention has been given to the development of forage crops and agricultural by-products or to the improvement and the management of natural rangelands. Insufficient rainfall and overgrazing has contributed to a serious soil and vegetative cover deterioration of existing rangelands and feed deficits are continuing.

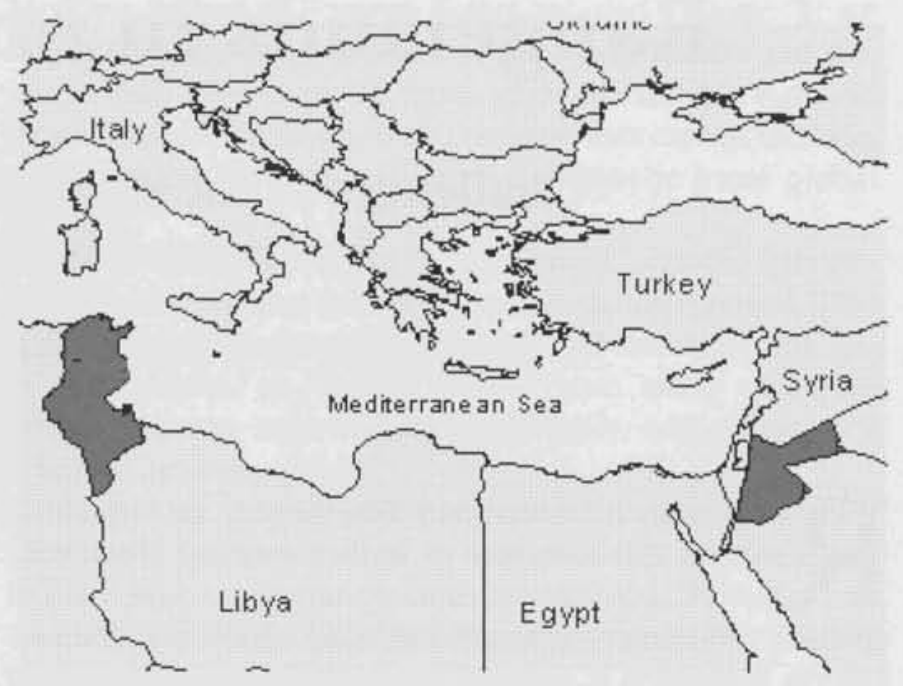

Locality map of Tunisia (left) and Jordan (right).

Tunisian territory covers more than $16 \mathrm{M}$ hectares. Forest and natural rangelands occupy around $33 \%$ of the total area. The most obvious constraint on livestock production in the country is the shortages of animal feed. Rangeland areas have become degraded as a result of overstocking resulting in a severe reduction of carrying capacity. Rangelands have been converted to cereal and fruit trees plantations, whose contribution to annual feed requirements is more and more limited. Supplementation from other sources of forage, by-products and concentrates is becoming increasingly needed. The changes of marginal land and other land areas have contributed to huge annual reductions of animal feed. For example, between 1979 and 1988 , areas covered by cultivated lands increased by $17.7 \%$.

Areas with less than $250 \mathrm{~mm}$ precipitation, lands that once were productive grazing lands, are now converted to marginal farmland producing cereal crops only 2 years out of 5. During years of adequate fall rains farmers plant cereal which may be grazed if spring rainfall is low. During years of inadequate fall rains farmers keep their lands for grazing. The improvement toward the restoration of the soil vegetative cover has become difficult or impossible.

The high rate of crop failures due to inadequate and inconsistent rainfall has resulted in much of the marginal cropping reverting back to grazing, leading to low value forage plants as the prominent source of livestock feed. Palatable range species have partially or fully disappeared and the soil degradation reached $75 \%$ in some areas. Up until 1960, livestock numbers were highly affected by the climatic conditions which periodically reduced the available forage. The cyclic periods of drought led to huge animal losses. Since 1960, even though rangelands continue to decrease, the impact of drought periods on livestock feed resources decreased due to the progressive modifications in 
the livestock production and feeding systems. Farmers adopted diversified types of storable feed resources such as hay, urea treated or untreated straw, silage, secondary cereal crops, by-products and industrial feeds (concentrate, alfalfa pellets). In cases of serious droughts, government agencies organise and encourage the importation of necessary feeds. No substantial reductions in livestock numbers occurred since 1979.

Nowadays, Tunisia counts around 6.5 million sheep, 1.3 million goats, and 748,000 cattle. The total feed need is around 4,400 million Forage Units (FU), with a total amount of supplemented feed stuff based on imported barley grains topping the 670,000 tons mark (1995 figures). Due to the evolution in land use (expansion of cereal cropping and arboriculture), the contribution of rangelands decreased by about $39 \%$ in 25 years. In 1964, rangeland production covered $84 \%$ of the feed needs of central and southern regions and $63 \%$ of the total livestock need of the country. This contribution has decreased to around 20 to 25 percent during the last decade. In 1990, a favourable year, the contribution was only about $24 \%$ due to the expansion of cereal cropping and arboriculture upon rangelands. There is an even more serious problem in southern Tunisia, where more than $30 \%$ of the total sheep population is raised, with very unproductive rangelands. Moreover, a large part of the extreme southern rangelands are unused due to lack of watering points, rural roads and absence of shading zones.

Today, rangeland total production is around 1,200 million forage units during rainy years, decreasing to less than half during dry years. Livestock feed needs are around 4,400 million forage units to reach 5,200 million forage unit in year 2006. Rangelands contribute by between 10 and $25 \%$ in livestock feeding, while fallow provides 10 to $20 \%$. Cultivated forage crops provide 10 to $15 \%$, agricultural and industrial by-products provide 25 to $30 \%$ and feed concentrates (barley and alfalfa pellets) provide 15 to $40 \%$ of livestock feeding.

Recognizing the seriousness of range degradation and feed deficits, the government has strengthened its program for the development of degraded natural rangelands. For decades, in order to face an increasing demand of animal products, the government implemented measures to alleviate the impact of feed deficits on livestock management by ensuring the implementation of intensified and integrated livestock programs. Some of these measures are:

a. improving forage production to increase animal feed resources,

b. combating land degradation, land erosion and desertification phenomena,

c. increasing of training programs for the range management specialists,

d. promoting applied field research programs to diversify the forage species related to each specific bioclimatic zone, and e. instigating subsidies and price support policies.

Several local major range improvement achievements during the last two decades reached around 711,000 hectares using various techniques centred around improving range condition and community awareness. For instance, some of these development programs improved some degraded lands by planting about 211,500 ha of spineless cactus and about 225,000 ha of shrubs, such as saltbushes (Atriplex nummularia and $A$. halimus), acacia cyanophylla, alfalfa shrubs and other native shrub species and deferring about 274,500 hectares.

These various schemes and programs have, at various extents, reduced land degradation of Tunisian rangelands. A long-term concerted effort is still needed to make these programs deliver better outcomes.

\section{Sustainable Management Of These Rangelands}

It has been widely publicised, and rightly so, that rangelands have been greatly overgrazed and degraded, particularly in developing countries. How can farmers sustainably manage rangelands when survivorship is in question? How can farmers think sustainability when their livelihood is dependent on few underfed weak grazing animals?

Unlike farmers in developing countries, those in developed countries live a life of funding availability for relatively many kinds of schemes, initiatives and programs. Many of the programs in developed countries, such as the USA and Australia, are part of a bigger focused strategic framework. And that has been a strong basis for their success.

For any success stories in rangeland management in Tunisia and Jordan, therefore, it is believed that there is a pressing need for very focused targeted subsidy programs funded and incorporated mainly by the World Bank and FAO development programs:

a. Education and technical expertise of rangeland specialists

b. Provision of low interest loans to governments to provide subsidies to those relying on rangelands and livestock for their life. A set of very focused criteria is to be a measure of eligibility for assistance

c. Education of farmers about on-farm rangeland improvement strategies in conjunction with monthly subsidies to farmers relying on rangelands as sources of income, are direct remedies to the problem of overgrazing and rangeland degradation.

These initiatives/programs would, in turn, strengthen not only farmers' understanding of natural resource management, but also their appreciation for what the land provides for them and the generations that follow. Social aspects of farming are extremely important for younger farmers to respect the land and take the torch to finish what the ancestors have tried to accomplish. Organisations, such as the World Bank and FAO, should revisit the ways they implement these types of interventions. For instance, full consul- 


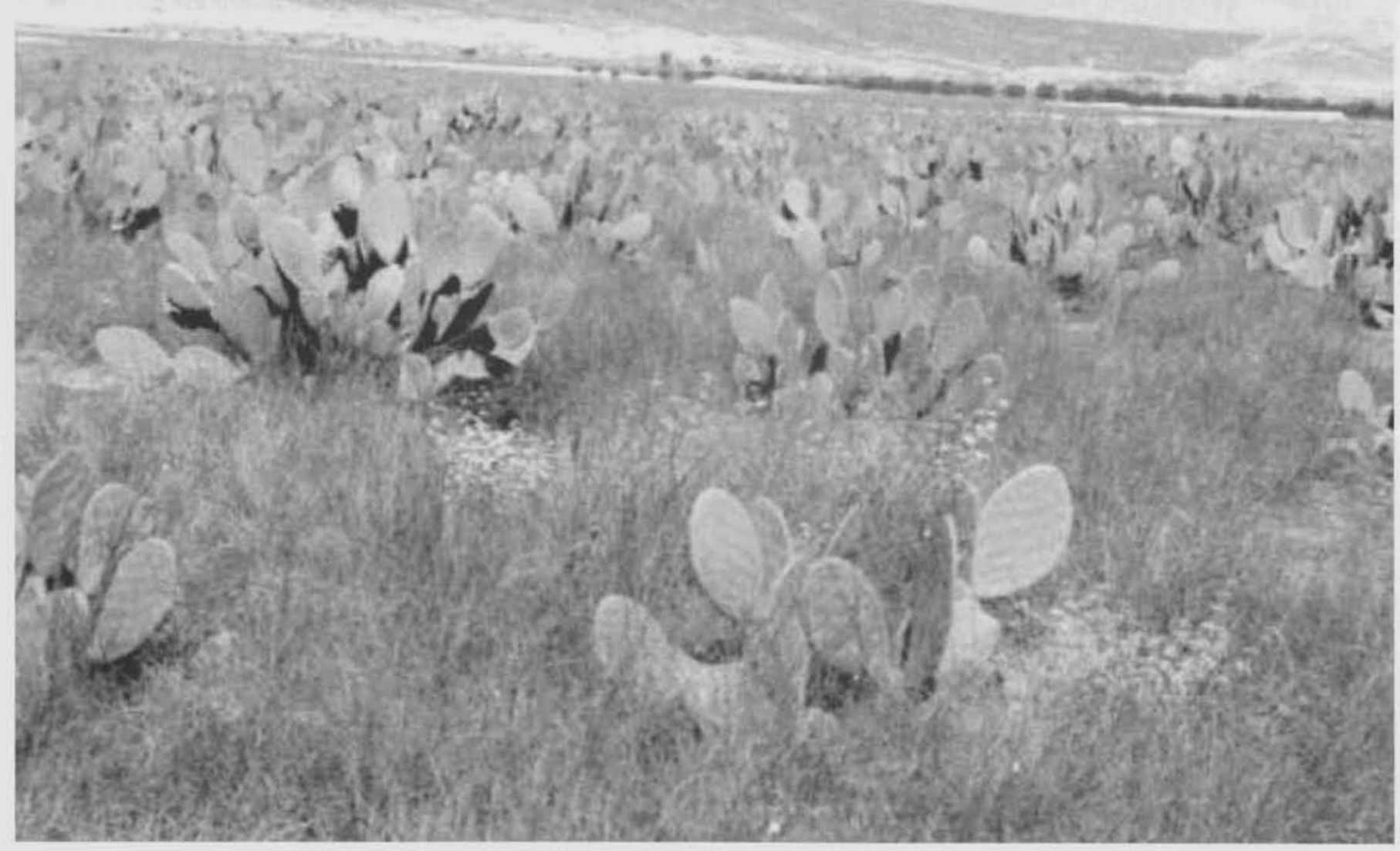

tations/collaborations with farmers, in close partnership with government agencies, is required in order to achieve positive outcomes. This does not entail an increase in funding but rather a better use of the current support.

Authors are: 'Rangeland Ecologist, Agency for Food and Fibre, QDPI, Australia; ${ }^{2}$ Associate Professor of Range Ecology. Faculty of Agriculture, Jordan University of Science. Irbid, Jordan; ${ }^{3}$ Regional Manager. Office de l'Elevage et des Paturages, Tunisia.

\section{References}

FAO. (1988). Jordan small ruminant development projectIdentification report. 26/88 IF-JOR 5-FAO, Rome.

FAO. (1994). Sheep Production Under Extensive Systems in the Near East. Jordan pastoral system: A case study. Near East Regional Office Food and Agriculture Organisation of the United Nations. Cairo, Egypt.

Jaradat, A.A. (1988). An Assessment of Research Needs and Priorities for Rainfed Agriculture in Jordan. Published in Jordan by the United States Agency for International Development.
Le Houérou, H.N., (1969). Contribution des différentes ressources alimentaires a la couverture des besoins du cheptel en 1964 in: Programme de développement de la production fourragère et de l'elevage, FAO, 1998.

Le Houérou, H.N. and C.H. Host. (1977). Rangeland production and annual rainfall relations in the Mediterranean basin and in the African Sahel-Sudanian Zone. J. Range Manage, 10:265-270.

Ministère de 1'Agriculture. (2000). Resultats de l'enquète sur le suivi de la campagne agricole 1998-1999.

Noy-Meir, I. and N.G. Seligman. (1979). Management of semi-arid ecosystems in Israel. In Walker, B.H. (ed). Management of Semiarid Ecosystems, Elsevier Sci. Pub. Co., Amsterdam.

Park, B.C. (1955). Use of photo mosaics as a base for range resource inventory in the Hashemite Kingdom of Jordan. J. Range Manage. 8:257-264.

Tiedeman, J.A. and S. Chouki. (1989). Projet d'amélioration et de gestion des parcours de la Tunisic Centrale. Rapport Final.

World Bank. (1995). Une strategie pour le développement des terrains de parcours en zones arides et semi-arides. Rapport technique Tunisie. 